\title{
Solar Processes for the Destruction of Hazardous Chemicals
}

Prepared for the American Chemical Society Symposium on Renewable Energy and the Environment, Denver, Colorado, March 28-April 12, 1993

Daniel M. Blake

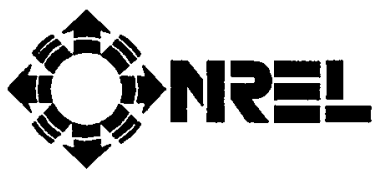

National Renewable Energy Laboratory (formerly the Solar Energy Research Institute) 1617 Cole Boulevard Golden, Colorado 80401-3393

A Division of Midwest Research Institute Operated for the U.S. Department of Energy under Contract No. DE-AC02-83CH10093

June 1993 


\title{
Solar Processes for the Destruction of Hazardous Chemicals
}

\author{
Daniel M. Blake
}

National Renewable Energy Laboratory

Golden, Colorado 80401-3393 


\begin{abstract}
Solar technologies are being developed to address a wide range of environmental problems. Sunlight plays a role in the passive destruction of hazardous substances in soil, water, and air. Development of processes that use solar energy to remediate environmental problems or to treat process wastes is underway in laboratories around the world. This paper reviews progress in understanding the role of solar photochemistry in removing man-made chemicals from the environment, and developing technology that uses solar photochemistry for this purpose in an efficient manner.
\end{abstract}

\title{
INTRODUCTION
}

Renewable forms of energy have a central role to play in reducing and correcting the negative impact of human activity on the environment. Solar energy is unique among the renewable energy forms in that it can be applied directly to mitigating problems created by past and continuing release of manmade chemicals into the environment. This chapter will briefly review the ways that sunlight degrades hazardous chemicals in the environment, and the development of technologies that can use sunlight for that purpose.

The past release of a wide range of substances into the environment as the result of human activity has created conditions at many sites that pose a risk to human health and the well-being of large and small ecosystems. Existing contamination affects air, water, and soil, and will ultimately cost billions of dollars to correct. Preventing further release of hazardous substances is a high priority for industry as it develops new processes and products. ${ }^{1}$

The involvement of sunlight in the removal of synthetic chemicals from the environment is well documented. A few examples will serve to illustrate how solar energy plays a part in the destruction of a variety of chemicals in the environment under ambient conditions. These naturally occurring processes can be termed passive solar photochemistry because they do not require human intervention. These processes illustrate the kinds of photochemistry that can be done under solar conditions, and the ways in which the chemical reaction path taken depends on the type of substance and the medium.

The classes of photochemical processes that have been observed to occur under solar conditions are briefly described below. For a more detailed discussion of the interaction of light with matter the reader may consult some of the standard sources on photochemistry. ${ }^{2}$ Representative photochemical processes include:

a. direct photochemistry where light is absorbed by a compound, $\mathrm{A}$, and the excited state, $\mathrm{A}^{*}$, goes on to react with oxygen and/or water to be mineralized to carbon dioxide or to produce small molecules that are, ideally, environmentally benign or can be further broken down.

$$
A \stackrel{h v}{\longrightarrow} A^{*} \stackrel{\mathrm{O}_{2} \mathrm{H}_{2} \mathrm{O}}{\longrightarrow} \text { Products }
$$


b. photochemistry of molecules adsorbed on surfaces, $A(\mathrm{ads})$, where the adsorbed compound is excited to a reactive state by absorption of light and is degraded.

$$
A+\text { surface } \rightarrow A(a d s) \stackrel{h v}{\longrightarrow} A^{*}(\text { ads }) \stackrel{\mathrm{O}_{2}, \mathrm{H}_{2} \mathrm{O}}{\longrightarrow} \text { Products }
$$

c. sensitized formation of singlet oxygen or hydroxyl radical by energy transfer from an electronically excited donor, $\mathrm{D}^{*}$, to oxygen.

$$
\begin{aligned}
D \stackrel{h v}{\longrightarrow} D^{*} \stackrel{\mathrm{O}_{2}\left({ }^{3} \mathbf{\Sigma}_{g}\right)}{\longrightarrow} \rightarrow \mathrm{O}_{2}\left({ }^{1} \mathrm{\Sigma}_{8}\right) \\
\stackrel{\mathrm{H}_{2} \mathrm{O}_{3} \mathrm{O}_{2}}{\longrightarrow} \rightarrow \mathrm{OH}
\end{aligned}
$$

d. photocatalytic oxidation, where light of wavelength greater than the band gap of a semiconductor, for example $\mathrm{TiO}_{2}$, promotes an electron from the valence band to the conduction band. The resulting valence band hole may either directly oxidize a molecule of contaminant or oxidize water to produce a hydroxyl radical.

$$
\mathrm{TiO}_{2}(\mathrm{~s}) \stackrel{h v}{\longrightarrow} \mathrm{TiO}_{2}(\mathrm{~s}) \stackrel{\mathrm{O}_{2}, \mathrm{H}_{2} \mathrm{O}}{\longrightarrow} \mathrm{OH}+\mathrm{HO}_{2}
$$

e. photo-Fenton chemistry in which light absorption by iron(+3) hydroxo complexes can result in electron transfer to give a hydroxyl radical and iron $(+2)$.

$$
\mathrm{Fe}(\mathrm{OH})_{a q}^{+2} \stackrel{h v}{\longrightarrow} \mathrm{Fe}_{a q}^{+2}+\mathrm{OH}
$$

\section{SOLAR CHEMISTRY FOR THE DESTROYING HAZARDOUS CHEMICALS}

The high energy cutoff of the solar spectrum at the earth's surface is about $295 \mathrm{~nm}^{3}$ This limits the types of organic compounds that will undergo direct photochemical reactions in sunlight to those that have absorption bands extending into the near ultraviolet (300-400 nm). In general these will be substituted aromatic compounds or compounds having extended systems of conjugated double bonds. Adsorption of molecules on surfaces may cause red shifts of the absorption spectra that will make them susceptible to solar photochemistry. ${ }^{4}$ 


\section{Solar Chemistry in the Environment}

The solar photochemical destruction of chlorinated dibenzo-p-dioxins adsorbed on surfaces is believed to be a route for removing such compounds from the environment. This has been shown to occur for compounds adsorbed on soil ${ }^{5,6}$ and grass foliage. ${ }^{7} \quad$ Similar mechanisms may be important for photochemical oxidation of compounds in air by involvement of minerals in aerosol form.

The solar photochemistry of organic compounds in natural waters is believed to be important in the removal of synthetic compounds. Three kinds of processes have been proposed. The first is photocatalytic oxidation mediated by naturally occurring semiconducting oxides of iron or titanium ${ }^{8.9}$. The second is the sensitized fornation of hydroxyl radicals by excited states of humic substances ${ }^{10}$. The final process is Fenton type chemistry caused by the presence of soluble iron compounds or perhaps iron oxides. This mechanism may also be important in cloud water. ${ }^{11,12}$ Hydroxyl radicals are believed to be the active agent responsible for the initial attack on the target compound in each case. The combination of hydroxyl radicals may be at least partially responsible for the formation of hydrogen peroxide in cloud water. ${ }^{13}$

\section{Solar Technology for Environmental Remediation}

The. role of sunlight in destroying organic compounds in the environment is well established. The development of technology that will use solar energy for this purpose in a controlled manner is a challenge that is being actively pursued in laboratories and at the engineering scale all over the world. Passive solar photochemical destruction of harmful substances in air, water, and soil is free. However, when reactors and solar collection hardware are used costs are incurred. The goal of research and development being performed worldwide is to develop cost effective technology that can efficiently utilize solar photochemistry in active processes for destroying hazardous chemicals.

The kinds of processes that have been or are currently being considered include both thermal and photochemical technologies. On the thermal side pyrolysis and oxidation and catalytic steam reforming of hazardous compounds have been studied, primarily at the laboratory scale. ${ }^{14}$ The cutoff of the solar spectrum at about $295 \mathrm{~nm}$ precludes direct photochemistry for many classes of organic compounds that are considered environmental hazards. This requires that processes, such as b - e discussed earlier be considered.

\section{Direct, High Temperature Photochemistry}

The University of Dayton Research Institute working under Subcontracts from the National Renewable Energy Laboratory (NREL) has extensively explored the effects of high light flux on the destruction of organic compounds at temperatures in the range of 200-1000 C. Compounds such as napthalene, chlorobenzene, and nitrobenzene that have some absorbance in the near UV region of the solar spectrum show increased levels of destruction when irradiated compared to the pure thermal reactions at the same temperatures. ${ }^{15,16}$

This effect was tested under solar conditions in a series of experiments conducted by NREL at solar furnaces at White Sands Proving Ground and Sandia National Laboratories. The effects of light on the high temperature destruction of 1,2,3,4-tetrachloro-p-dibenzodioxin are illustrated in Figure 1 . The experiment demonstrated increased destruction when the reactor was irradiated with the full solar 
spectrum compared to when a $450 \mathrm{~nm}$ cutoff filter was placed in the light path. ${ }^{17}$ This work is now being extended to the pilot scale in a joint project funded by the United States Departments of Defense and Energy, and Environmental Protection Agency.

\section{Dye Sensitized Oxidation}

Dye sensitized formation of singlet oxygen and its application to the destruction of organic compounds and disinfection of effluent from a municipal sewage treatment plant has been investigated extensively. A number of dyes that absorb strongly in the visible region of the solar spectrum sensitize the formation of singlet oxygen. This has been tested on a range of organic compounds and pilot plants operated for both removing organic compounds from contaminated water and for disinfecting sewage plant effluent to use for crop irrigation. ${ }^{18,19,20}$ Figure 2 shows a pilot system that was used for the latter purpose in Israel.

\section{Photocatalytic Oxidation}

Oxidizing organic compounds in water with irradiated semiconductors is the subject of a large body of research. The author has a data base containing over 600 references to work on this and related areas. There are a number of reviews that cover aspects of this work ${ }^{21,22,23}$ as well as papers that discuss the mechanism and kinetics of the process. ${ }^{24,25,26}$ In general the process requires a semiconductor, light with higher energy than the bandgap of the semiconductor, and a suitable oxidizing agent. Various types of the anatase form of titanium dioxide have been found to be the most effective photocatalyst and oxygen or hydrogen peroxide are the oxidizing agents of choice.

Solar experiments have been reported by a number of workers. ${ }^{27,28,29,30}$ Large scale tests have been conducted by the solar research programs in the United States and Europe. The first large scale outdoor tests used existing solar hardware modified to carry out photochemical reactions. ${ }^{31}$ A test on actual groundwater was carried out at a superfund site at Lawrence Livermore National Laboratory (LLNL) by NREL, LLNL, and Sandia National Laboratory. Groundwater contaminated with trichloroethylene (TCE) was treated using a system constructed from parabolic troughs with a borosilicate glass pipe at the focus for a reactor. The system is shown in Figure 3. The contaminated groundwater was mixed with titanium dioxide powder and pumped through the reactor. The TCE level was successfully reduced from about $300-500 \mathrm{ppb}$ (micrograms per liter) to $<5 \mathrm{ppb}^{32}$

Experiments have also been done at the European solar test facility at Almeria, Spain. The Spanish have fitted existing two-axis tracking parabolic troughts with borosilicate glass reactors, shown in Figure 4, and studied the destruction of pentachlorophenol and dichloroacetic acid with this system. ${ }^{33,34}$

The mechanism of action of the semiconductor-initiated photochemistry predicts that the rates and efficiencies of the oxidation reactions will increase as the square root of light flux at low organic concentrations. $^{24}$ Hence multiple sun reactors will be less efficient than reactors using the ambient intensity of sunlight. This was shown to be the case in a test using the LLNL system. ${ }^{32}$ For this reason a second generation of tests has been done using solar reactors that do not concentrate the sunlight. One-sun or non-concentrating reactors are shown in Figures 4 and 5. The first was tested at the Plataforma Solar in Almeria, Spain in collaboration with a group from the Institute fur Solarenergieforschung in Hanover, Germany. The second was developed by American Energy 
Technologies (AET), Inc. for treating contaminated groundwater at Tyndall Air Force Base in Florida. ${ }^{35}$ In addition to avoiding the square root penalty for increased light flux, the one-sun reactors can use both the direct beam and diffuse components of the near UV part of the solar spectrum, and they eliminate losses due to reflector surfaces,. A number of innovative reactors that operate with low solar flux or at one sun have been evaluated at NREL. ${ }^{36,37}$ Examples are shown in Figures 6 and 7. Cost studies have shown that under most conditions the cost of solar photons is competitive with the cost of photons from electric lamps. ${ }^{38,39,40}$

\section{New Developments}

The photocatalytic oxidation of low molecular weight hydrocarbons in the gas phase was the subject of considerable attention in the 1970s and 1980s partially because of the search for solar technologies for the production of chemicals. The goal was to produce oxygenated products such as alcohols, aldehydes and ketones. ${ }^{41,42}$ Interest waned when the price of oil dropped in the latter part of the '80s. The report that trichloroethylene could be rapidly oxidized in air over irradiated titanium dioxide ${ }^{43}$ revived interest in the gas phase oxidation process as a potential method for reducing emissions of volatile organic compounds and as a tool for environmental remediation. There is a great deal of research being done, but only bench scale tests have been reported to date. ${ }^{44,45}$

Other developments include processing water to remove metal ions and a method for cleaning up ocean oil spills. Photocatalytic reduction of metal ions by the conduction band electrons at irradiated semiconductor surfaces has been demonstrated and considered as a potential solar process for the removal of heavy metals from contaminated water. ${ }^{46,47}$ Development of $\mathrm{TiO}_{2}$ - coated hollow glass microspheres for use in decomposition of organic compounds on the surface of water is underway. The coated beads can be applied to oil spills in order to break the oil down into harmless substances when exposed to sunlight. ${ }^{48}$

Cost estimates have been made that compare the cost of solar and conventional photochemical processing for environmental remediation. ${ }^{38,39,40}$ Figure 8 gives a graphical presentation that compares the cost of photons from electric lamps with photons supplied by one-sun solar collectors. As expected photons from the one-sun systems are less expensive than for the concentrating systems because of the lower hardware costs. The results show that solar photons can be less expensive than photons from lamps in many parts of the United States when low, but realistic, collector costs are achieved.

\section{CONCLUSION}

The destruction of hazardous substances by solar processes has amply demonstrated.

Commercialization of solar technologies requires that they be shown to be cost effective, and that they overcome the barriers normally encountered by new technology as well as barriers that are unique to solar processes. The barriers include:

1) the risk associated with adopting a new technology,

2) a general lack of familiarity with photochemical processes on the part of industry, and

3) using the sun as a light source introduces new process requirements that deal with the intermittent nature of this source of photons. 
It is likely that cost competitive solar technologies for environmental cleanup applications will become commercially available in the next few years. Technical developments are being driven by the need for innovative tools to treat the wide range of environmental problems that have been created by past practices.

\section{Figure Captions}

1. Effect of solar near ultraviolet light on the destruction of 1,2,3,4-tetrachloro-p-dibenzodioxin.

2. Pilot plant for the dye sensitized disinfection of sewage plant effluent at Herzliyya City, Israel.

3. Pilot plant for the photocatalytic removal of chlorinated solvents from groundwater at Lawrence Livermore Laboratory, California.

4. Pilot plant for studying solar photocatalytic removal of organic compounds from water. Background, two-axis tracking parabolic trough system, foreground, non-concentrating thin film reactor. Location, Plataforma Solar - Almeria, Spain.

5. Non-concentrating reactor designed by AET, Inc. for treating contaminated groundwater at Tyndall Air Force Base, Florida.

6. Reactor with compound parabolic concentrators designed by IST, Inc. and tested at NREL.

7. Artist's concept of a solar photocatalytic water detoxification system using ponds or tanks as onesun reactors.

8. Comparing the cost of photons from lamps and from the sun as a function of solar collector cost.

\section{REFERENCES}

1. Curran, M. A., Broad-based environmental life cycle assessment, Environ. Sci. Technol., 27, 430, 1993.

2. Scandola, F. and Balzani, V., Interaction between light and matter, in Photocatalysis Fundamentals and Applications, Serpone, N. and Pelizzeta, E., Eds., John Wiley and Sons, New York, 1989, chap. 2.

3. Myers, D. R., Cannon, T., and Webb, J. D., Terrestrial solar spectral ultraviolet measurements at the National Renewable Energy Laboratory, in Proc. SPIE-Int. Soc. Opt. Eng., Soc., 1764, PhotoOpt. Inst. Eng., Bellingham, WA, 1992, 350.

4. Kalyanasundraram, K., Photochemistry in Microheterogeneous Systems; Academic Press, New York, 1987, chap. 10.

5. Dougherty, E. J., McPeters, A. L., Overcash, M. R., and Carbonell, R. G., Theoretical analysis of a method for in situ decontamination of soil containing 2,3,7,8-tetrachlorodibenzo-p-dioxin, Environ. Sci. Tech. 27, 1993, 505. 
6. Kleatiwong, S., Nguyen, L. V., Hebert, V. R., Hackett, M., Miller, G. C., Mille, M. J., and Mitzel, R., Photolysis of chlorinated dioxins in organic solvents and on soils, Environ. Sci. Tech., 24, 1990, 1575 .

7. McCrady, J. K. and Maggard, S. P., Uptake and photodegredation of 2,3,7,8-tetrachlorodibenzo-pdioxin sorbed on grass foliage, Environ. Sci. Tech., 27, 1993, 343.

8. Cunningham, K. M., Goldberg, M. C., and Weiner, E. R., The aqueous photolysis of ethylene glycol adsorbed on goethite, Photochem. and Photobiol., 41, 1985, 409.

9. Korman, C., Bahnemann, D. W., and Hoffman, M. R., Environmental photochemistry: is iron oxide (hematite) an active photocatalyst? A comparative study: $\alpha-\mathrm{Fe}_{2} \mathrm{O} 3, \mathrm{ZnO}, \mathrm{TiO}_{2}, J$. Photochem. and Photobiol., A: Chem., 48, 1989, 161.

10. Haag, W. R. and Hoigne, J., Photo-sensitized oxidation in natural water via $\mathrm{OH}$ radicals, Chemosphere, 14, 1985, 1659.

11. Zuo, Y. and Hoigne, J., Evidence for photochemical formation of $\mathrm{H}_{2} \mathrm{O}_{2}$ and oxidation of $\mathrm{SO}_{2}$ in authentic fog water, Science, 260, 1993, 71.

12. Faust, B. C., Hoffmann, M. R., and Bahnemann, D. W., Photocatalytic oxidation of sulfur dioxide in aqueous suspensions of $\alpha-\mathrm{Fe}_{2} \mathrm{O}_{3}, J$. Phys. Chem., 93, 1989, 6371.

13. Kormann, C., Bahnemann, D. W., and Hoffmann, M. R., Photocatalytic production of $\mathrm{H}_{2} \mathrm{O}_{2}$ and organic peroxides in Aqueous suspensions of $\mathrm{TiO}_{2}, \mathrm{ZnO}$, and desert sand, Environ. Sci. Technol., 22, 1988, 798.

14. Nimlos, M. R. and Milne, T. A., Direct mass spectroscopic studies of the destruction of hazardous wastes. 1. Catalytic steam re-forming of chlorinated hydrocarbons, Environ. Sci. Tecnhnol., 26, $1992,545$.

15. Graham, J. L. and Dellinger, B., Solar thermal/photolytic destruction of hazardous organic wastes, Energy, 12, 1987, 303.

16. Graham, J. L., Dellinger, B., Klosterman, D., Glatzmaier, G., and Nix, G., Disposal of toxic wastes by using concentrated solar radiation, Emerging Technologies in Hazardous Waste Management II. ACS Symposium Series No. 468, Tedder, D. W. and Pohland, F. G., Eds., ACS, Washington, D.C., 1991, chap. 6.

17. Glatzmaier, G. C., Nix, R. G., and Mehos, M. S., Solar destruction of hazardous chemicals, J. Environ. Sci. Health, A25, 571, 1990.

18. Acher, A. and Saltzman, S., Photochemical inactivation of organic pollutants from water, Ecological Studies - Toxic Organic Chemicals in Porous Media, Gerstl, Z., Chen, Y.,Mingelgrin, U., and Yaron, B., Eds. 73, 1989, chap. 15.

19. Saltzman, S., Acher, A. J., Brates, N., Horowitz, M, and Geveleberg, A., Removal of phytotoxicity of uracil herbicides in water by photodecomposition, Pestic. Sci.,13, 211, 1982. 
20. Acher, A., Fischer, E., Zellingher, R., and Manor, Y., Photochemical disinfection of effluents pilot plant studies, Wat. Res., 24, 837, 1990.

21. Ollis, D. F.,Pelizzetti, E., and Serpone, N., Photocatalyzed destruction of water contaminants, Environ. Sci. Technol., 25, 1522, 1992.

22. Fox, M. A. and Dulay, M. T., Heterogeneous photocatalysis, Chem. Rev. 93, 341, 1993.

23. Matthews, Ralph W., Photocatalytic oxidation of organic contaminants in water: an aid to environmental preservation, Pure Appl. Chem., 64, 1285, 1992.

24. Webb, J. D., Blake, D. M., Turchi, C., and Magrini K., Kinetic and mechanistic overview of $\mathrm{TiO}_{2}$-photocatalyzed oxidation reactions in aqueous solution." Solar Energy Mat., 24, 584, 1991.

25. Gerischer, H. and Heller, A. The role of oxygen in the photooxidation of organic molecules on semiconductor particles, J. Phys. Chem., 95, 5261, 1991.

26. Turchi, C. and Ollis, D., Photocatalytic degradation of organic water contaminants: Mechanisms involving hydroxyl radical attack, J. Catal. 122, 178, 1990.

27. Reeves, P., Ohlhausen, R., Sloan, D., Pamplin, K., Scoggins, T., Clark, C., Hutchinson, B., and Green, D., Photocatalytic destruction of organic dyes in aqueous $\mathrm{TiO}_{2}$ suspensions using concentrated simulated and natural solar energy. Solar Energy, 48, 413, 1992.

28. Pelizzetti, E., Pramauro, E., Minero, C., and Serpone, N., Sunlight photocatalytic degradation of organic pollutants in aquatic systems, Waste Management, 10, 65, 1990.

29. Matthews, R. W., and S. R. McEvoy, S. R., Destruction of phenol in water with sun, sand and photocatalysis, Solar Energy, 49, 507, 1993.

30. Muszkat, L., Halmann, M., Raucher, D., and Bir, L., Solar photodegradation of xenobiotic contaminants in polluted well water, J. Photochem. Photobiol., A, 65, 409, 1992.

31. Pacheco, J., Prairie, M., and Yellowhorse,L., Photocatalytic destruction of chlorinated solvents with solar energy, ASME- JSME-JSES International Solar Energy Conference, Reno, NV, March 17, 1991.

32. Mehos, M., Turchi,C., Pacheco, J., Boegel, A. J., Merrill, T., and Stanley, R., Pilot-scale study of the solar detoxification of VOC-contaminated groundwater, American Institute of Chemical Engineers 1992 Summer Annual Meeting, Minneapolis, Minn, NREL/TP-432-4981, August 9, 1992.

33. Blanco, J. and Malato, S., Influence of solar irradiation over pentachlorophenol solar photocatalytic decomposition, in Proc. 1st Int. Conf. TiO ${ }_{2}$ Photocatalytic Purification and Treatment of Water and Air, London, Ont., November 8-13, 1992.

34. Bockelmann, D., Goslich, R., Nogueira, R. F. P., Weichgrebe, D., Jardim, W. F., and Bahnemann, D., Solar detoxification of polluted water: Comparing the efficiencies of parabolic trough reactor 
and a novel thin-film fixed-bed reactor, in Proc. 1st Int. Conf. TiO ${ }_{2}$ Photocatalytic Purification and Treatment of Water and Air, London, Ont., November 8-13, 1992, 187.

35. Turchi, C. S., Klausner, J. F., Goswami, D. Y., and Marchand, E., Field test results for the solar photocatalytic detoxification of fuel-contaminated groundwater, NREL/TP-471-5345, presented at Chemical Oxidation: Technologies for the Nineties, Third International Symposium, Nashville, TN, February 17-19, 1993.

36. Turchi, C. S. and Mehos, M. S., Solar photocatalytic detoxification of groundwater: development of reactor designs, Chemical Oxidation: Technologies for the Nineties, Secong International Symposium, Nashville, TN, February 19-21, 1992.

37. Pacheco, K., Watt, A. S., and Turchi, C. S., Solar Detoxification of water: outdoor testing of prototype photoreactors, ASME/ASES Joint Solar Energy Conference, Washington, D.C., April 4-8, 1993.

38. Turchi, C. S. and Link, H. F., Relative cost of photons from solar or electric sources for photocatalytic water detoxification, International Solar Energy Society 1991 Solar World Congress, Denver, CO, 17 August 1991.

39. Schertz, P., Kelly, D., and Lammert, L., Analysis of the cost of generating or capturing ultraviolet light for photocatalytic water detoxification systems, Final Report, Subcontract No. AF-2-11252-1, National Renewable Energy Laboratory, Golden, CO, 1992.

40. Turchi, C. S., Mehos, M. S., and Link, H. F., Design and cost of solar photocatalytic systems for groundwater remediation, Remediation, in press, 1993.

41. Pichat, P., Hermann, J.-M., Disdier, J., and Mozzanega, M.-N., Photocatalytic oxidation of propene over various oxides at $320 \mathrm{~K}$. Selectivity, J. Phys. Chem., 83, 3122, 1979.

42. Sakata, T. and Kawai, T., Photosynthesis and photocatalysis with semiconductor powders, Energy Resources through Photochemistry and Catalysis, Gratzel, M., Ed., Academic Press, New York, 1983, 332.

43. Raupp, G. B. and Dibble, L. A., Gas-solid photocatalytic oxidation of environmental pollutants, United States Patent 5,045,288, 1991.

44. Peral, J. and Ollis, D. F., Heterogeneous photocatalytic oxidation of gas-phase organics for air purification: Acetone, 1-butanol, butyraldehyde, formaldehyde, and m-xylene, J. Catal., 136, $1992,554$.

45. Nimlos, M. R., Jacoby, W. A., Blake, D. M., and Milne, T. A., Direct mass spectrometric studies of the destruction of hazardous wastes. 2. Gas-phase photocatalytic oxidation of trichloroethylene over $\mathrm{TiO}_{2}$ : Products and mechanisms, Environ. Sci. Technol., 27, 732, 1993.

46. Foster, N. S., Noble, R. D., and Koval, C. A., Reversible photoreductive deposition and oxidative dissolution of copper ions in titanium dioxide suspensions, Environ. Sci. Technol., 27, 350, 1993. 
11 D. M. Blake

47. Prairie, M. R., Evans, L. R., Stange, B. M., and Martinez, S. L., An investigation of TiO2 photocatalysis for the treatment of water contaminated with metals and organic chemicals, Environ. Sci. Technol., in press, 1993.

48. Heller, A. and Brock, J. R., Materials and methods for photocatalyzing oxidation of organic compounds on water, United States Patent 4,997,576, March 5, 1991. 


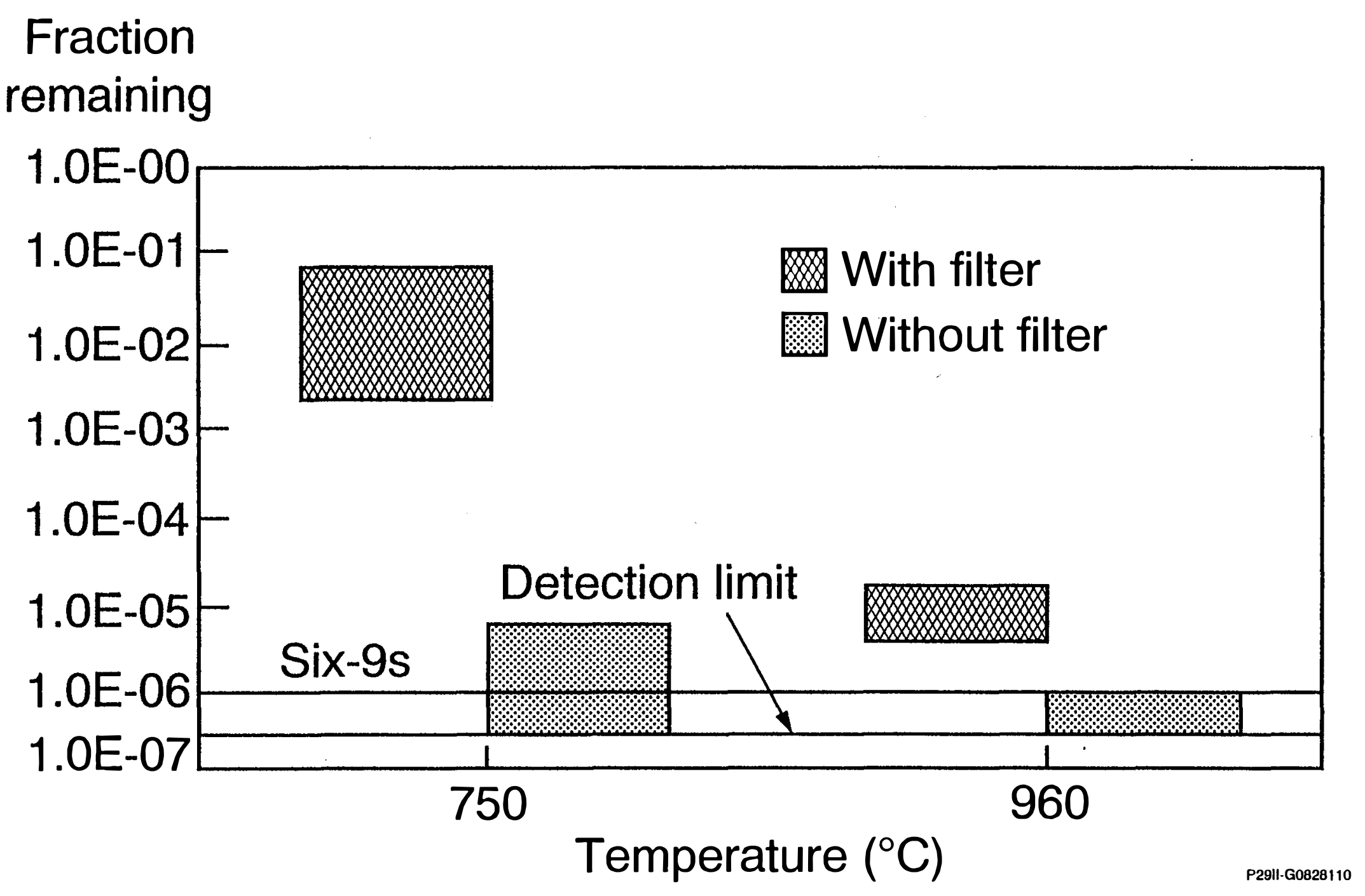




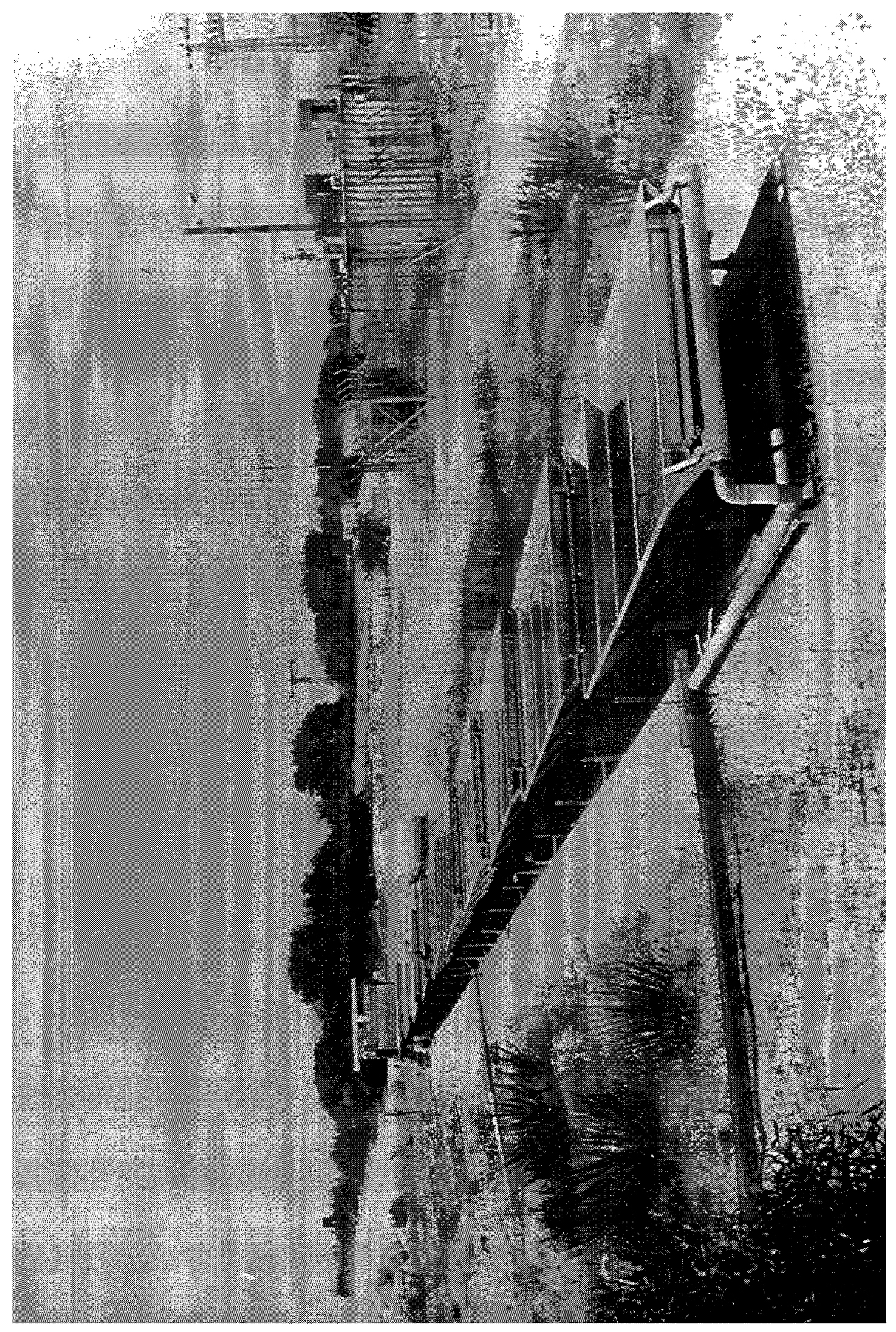




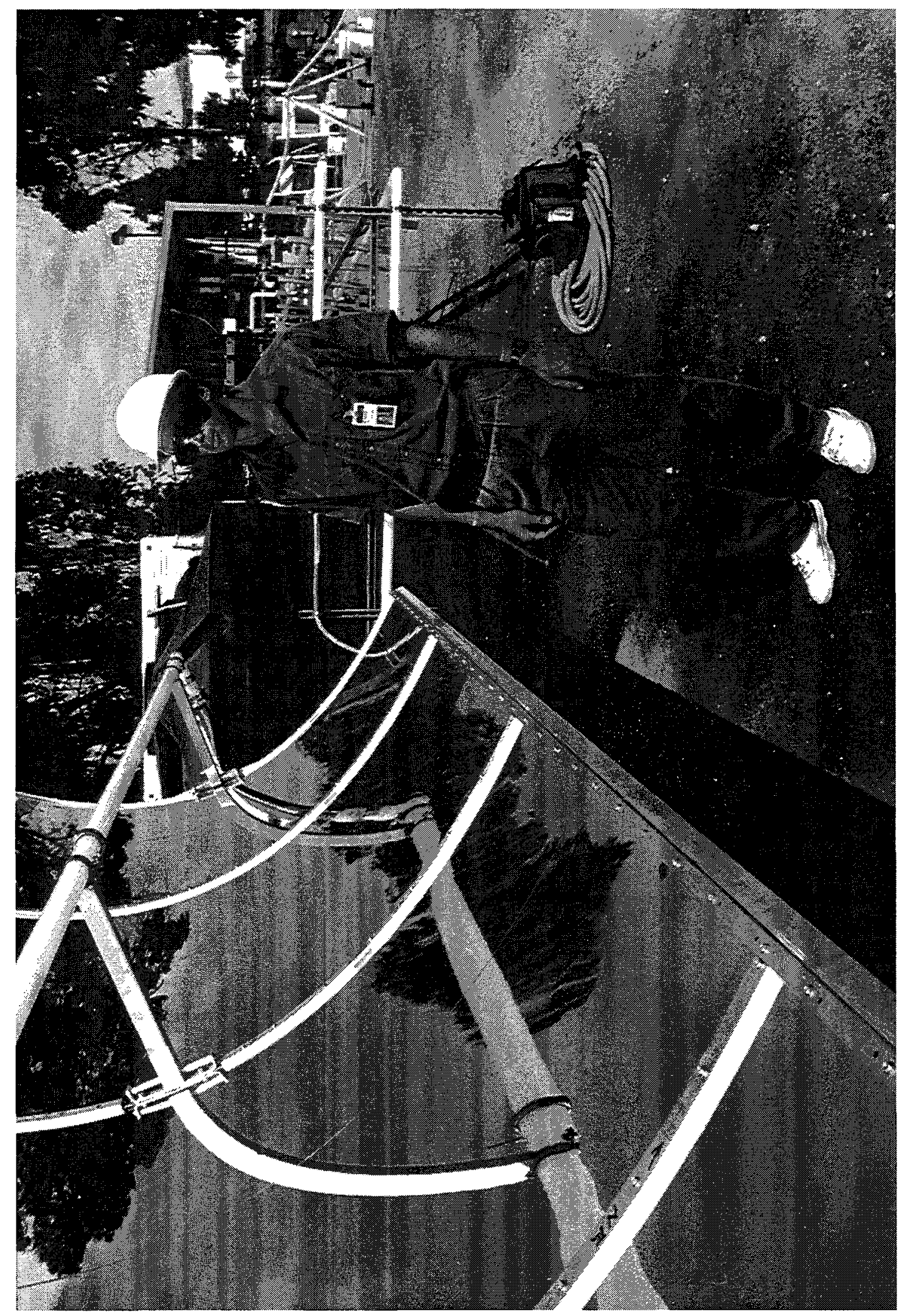




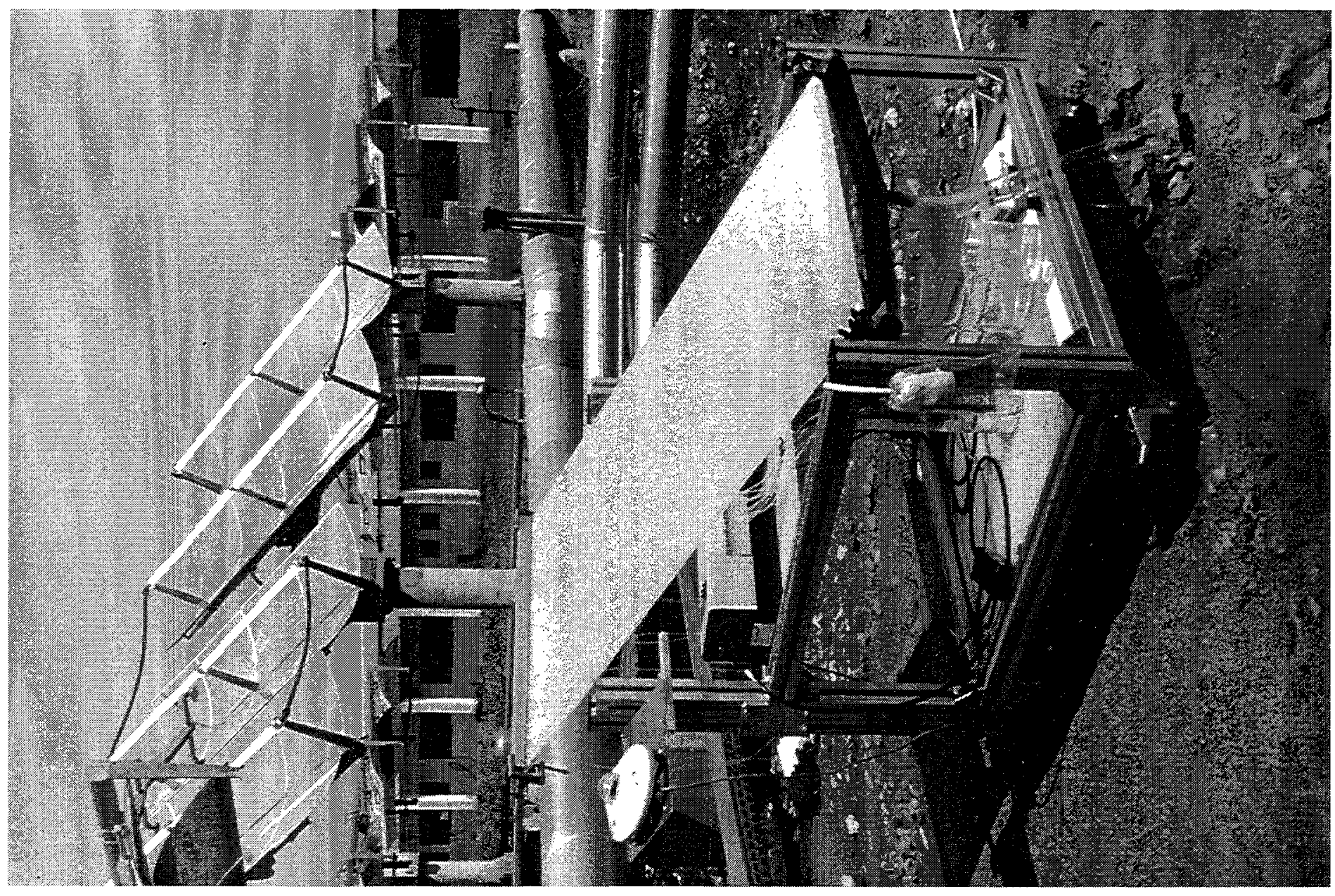




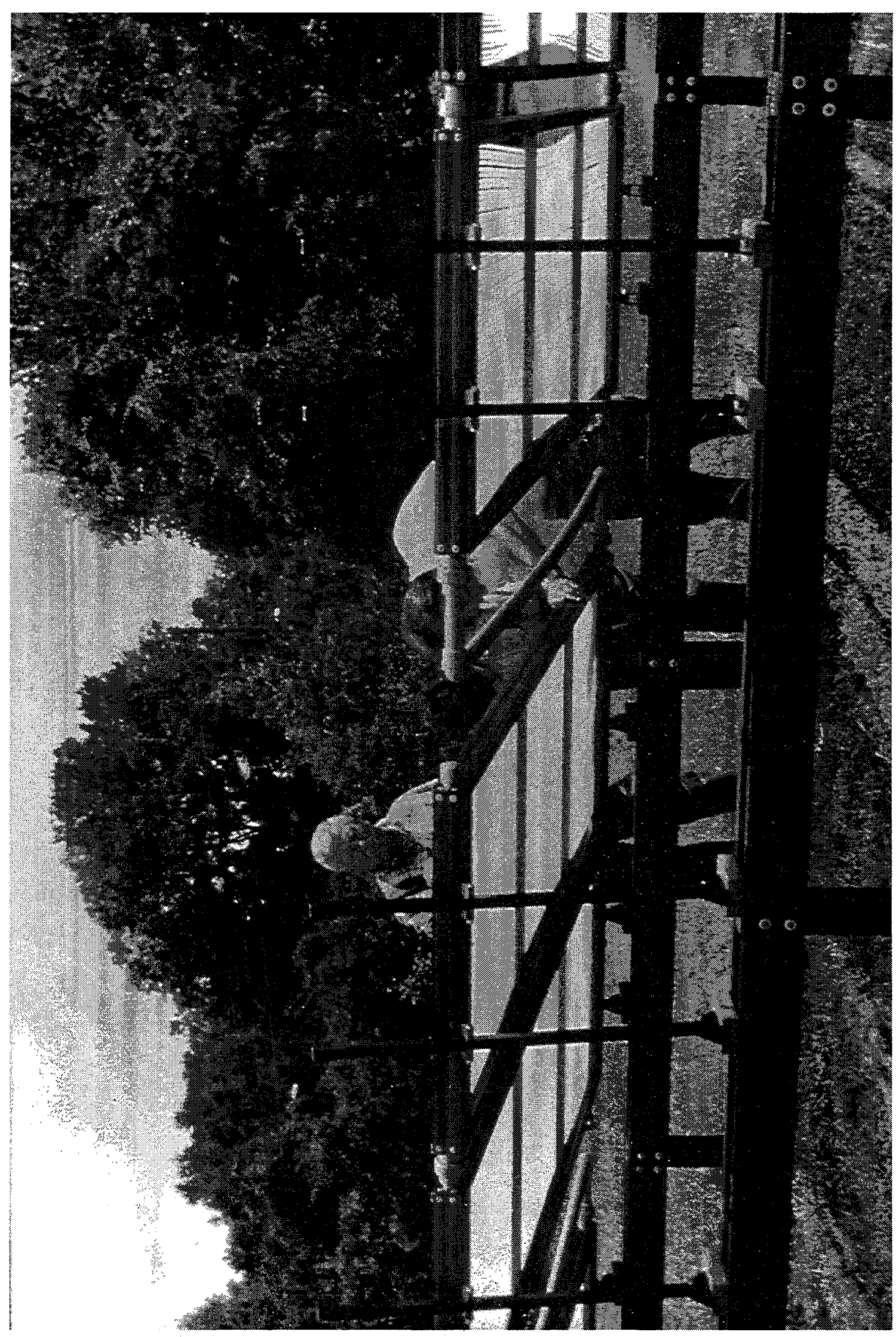




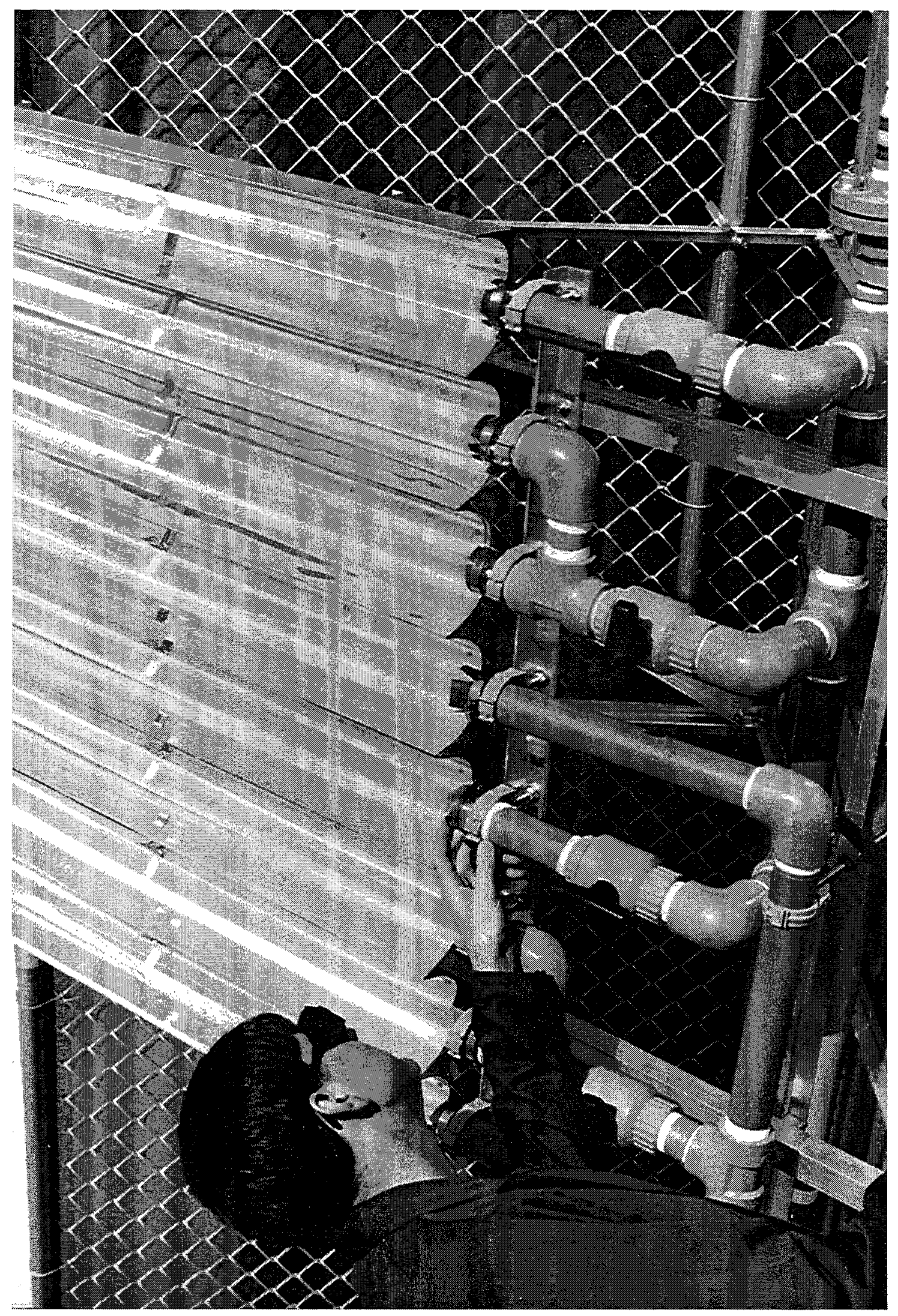




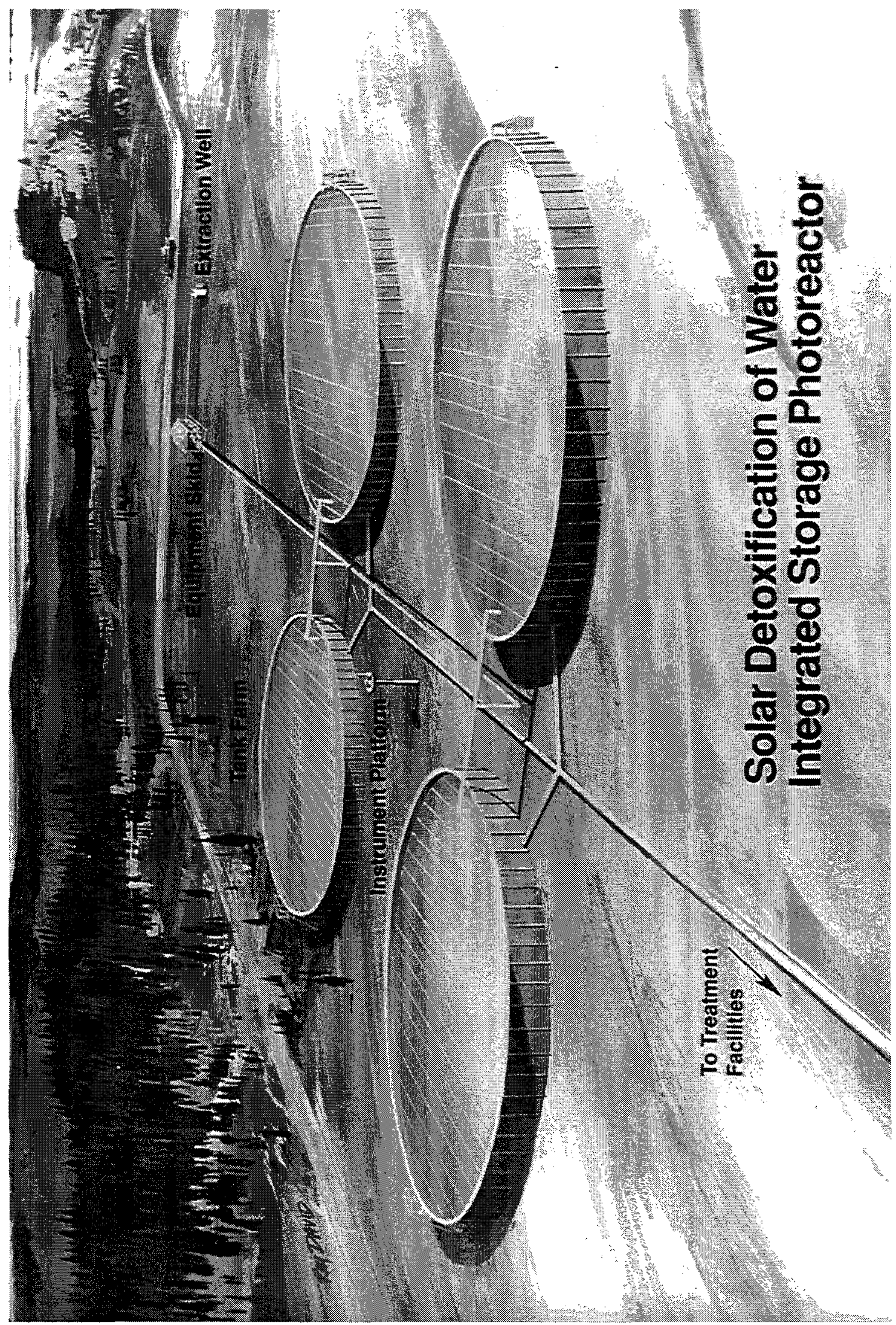




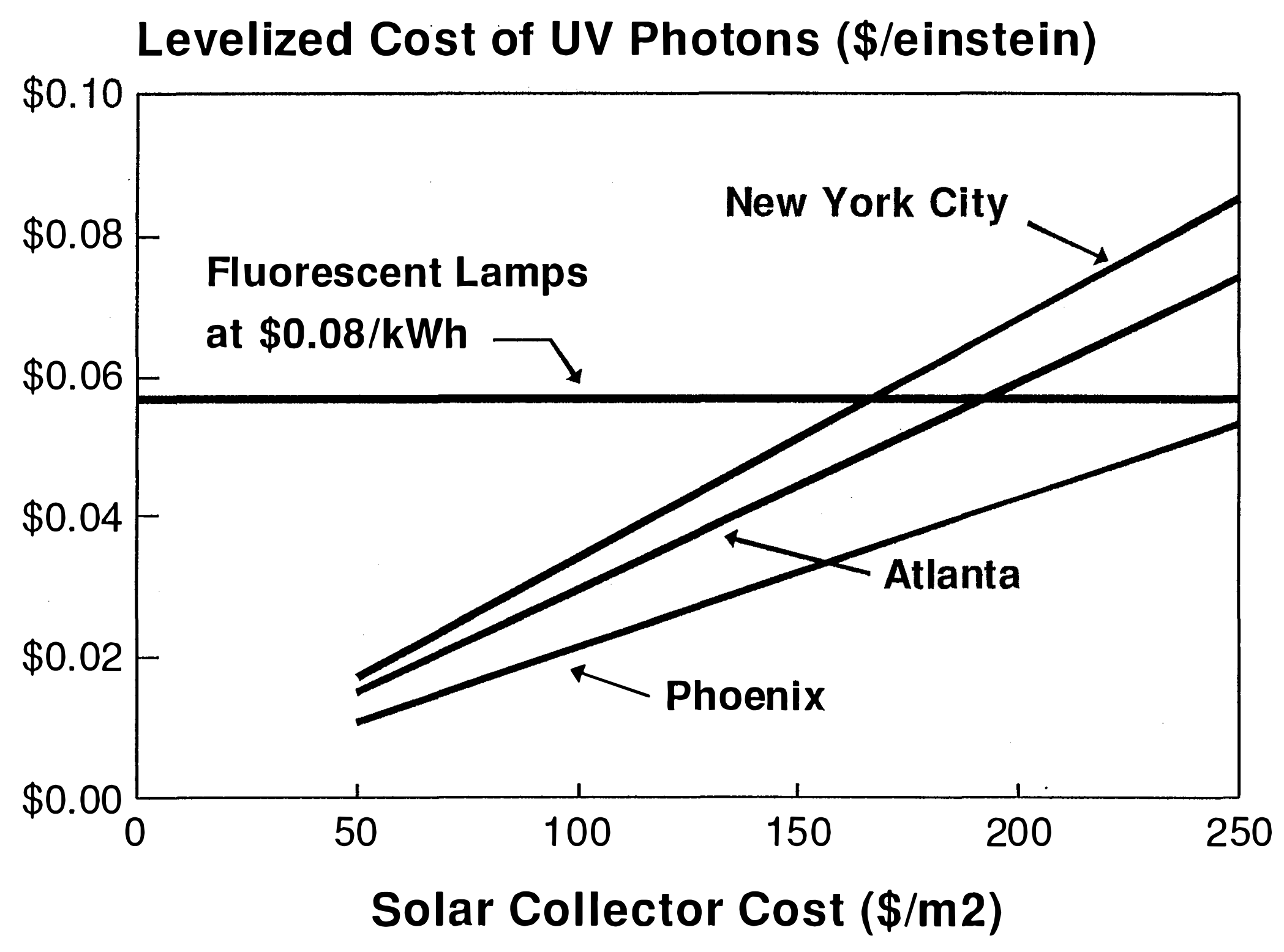

